\title{
Centuria prerrogativa y confusio suffragiorum. El sorteo en las elecciones romanas y el debate político del final de la República*
}

\author{
Prerogative centuria and confusio suffragiorum. \\ Sortition in Roman elections and the political debate at the end \\ of the Republic
}

VIRGINIE HOLLARD**

\begin{abstract}
Resumen: Este artículo recupera el estudio de un pasaje de una carta a César del Pseudo Salustio, en la que le sugiere el restablecimiento de un proyecto de ley de Cayo Graco destinado a reformar en profundidad el funcionamiento de la asamblea de centurias para las elecciones de magistrados superiores de Roma. Esta reforma consistiría en extender al conjunto del procedimiento de designación una operación de sorteo, que permitiera a las centurias de las cinco clases censitarias tener la misma oportunidad de votar a los candidatos que deseaban ver elegidos. Esta confusio suffragiorum permitiría disminuir el peso del dinero en las elecciones a las magistraturas más importantes de la ciudad. Después de recordar los principios fundamentales del voto romano y del sistema de centurias, nuestro estudio repasará el lugar del
\end{abstract}

\begin{abstract}
This article gets back on the study of an excerpt in a letter to Caesar, in which PseudoSallustus suggests him the reinstatement of a bill of Caius Gracchus. This bill aims at an in-depth reform of how the Centuriate Assembly operates in the context of the Senior Magistrates elections in Rome. The proposed reform would extend to all of the designation procedure a draw, allowing centuries of the five classes of citizens to have even opportunity to vote for the candidates they want to see elect. This confusio suffragiorum would reduce the weight of wealth in the elections of the most important magistrates of the city. After recalling the core principles of the Roman vote and of the centuriate organization, our study enlightens the role of the draw in the Centuriate Assembly elections
\end{abstract}

Fecha de recepción: 06/06/2017. Fecha de aceptación: 27/09/2017.

* La traducción al español, a cargo de Francisco Manuel Carballo Rodríguez y Jorge Costa Delgado, se ha hecho en el marco del proyecto de I+D: "La recepción de la Filosofía grecorromana en la Filosofía y las Ciencias Humanas en Francia y España desde 1980 hasta la actualidad” (FFI2014-53792-R).

** Profesora titular de Historia romana en la Universidad Lumière-Lyon 2, UMR 5189-HiSoMA. Temas de investigación: Historia romana, Derecho Público romano, Instituciones políticas, Historia del voto y de la democracia. Publicaciones: Hollard, V. (2010): Le rituel du vote. Les assemblées du peuple romain, Editions CNRS, París; Hollard, V. (2015): "La cité à Rome et dans le monde romain", Le monde romain 70 av. J.-C.-73 ap. J.-C., Ellipses, París. Quiero agradecer a Romain Meltz, profesor de Ciencia Política en la Universidad Lumière-Lyon 2, su relectura atenta y cuidadosa del texto y las largas conversaciones que tuvimos durante su elaboración. Contacto: virginie.hollard@wanadoo.fr 
sorteo en las elecciones de la asamblea de centurias a través del sistema de la centuria prerrogativa, antes de proponer una investigación de este proyecto de reforma analizando su valor ideológico y su eventual significado democrático.

Palabras clave: elecciones romanas, comicios centuriados, sorteo, democracia, ideología política. through the system of the prerogative centuria. It then presents a study of this reform project in terms of ideological value and Democratic meaning.

Keywords: roman elections, centuriate assemblies, draw, democracy, political ideology.

La reflexión sobre los modelos políticos antiguos opone tradicionalmente la democracia ateniense y el sistema oligárquico de la República romana al que se asocia, en la realidad de la vida política de la $\mathrm{Vrbs}$, únicamente a los ciudadanos más acomodados, aquellos a los que Cicerón llama los boni ciues. Mientras que la democracia ateniense utiliza principalmente el sorteo como herramienta para la designación de cargos, la República romana basa su sistema de selección de magistrados en elecciones, en la mayor parte de los casos, de carácter anual y colegiadas. Las elecciones romanas, de las que recordaremos sus principios elementales, tienen la característica principal de hacer participar (salvo excepciones en algunos momentos conflictivos de la vida política tardo-republicana) a los ciudadanos pertenecientes a las clases censitarias más altas de la escala social ${ }^{1}$. Este trabajo se propone abordar un proyecto de reforma del procedimiento de votación que incluía el sorteo, en el problemático contexto de las luchas políticas del final de la República. Este proyecto, iniciado por C. Graco, consistía en no hacer votar en orden sucesivo, tras la centuria prerrogativa, a las centurias de la clase ecuestre y después a las de las cinco clases censitarias, otorgando de ese modo la primacía y el poder electoral real a los ciudadanos más ricos de Roma, sino en llevar a cabo lo que un texto del Pseudo Salustio califica como confusio suffragiorum, esto es, una mezcla de todas las centurias sorteadas para votar por turnos. Esta "confusión de votos" situaba en condiciones de igualdad a todos los ciudadanos romanos independientemente de su riqueza. Este proyecto de ley, muy probablemente nunca aplicado, fue recordado a César en una carta de consejos políticos del Pseudo Salustio, con el propósito de eliminar la influencia de la riqueza en las elecciones, particularmente en las que se celebraban en la asamblea de centurias.

Cabe interrogarse, por tanto, acerca del significado de un proyecto de esas características, en qué medida podría reflejar la existencia de un debate ideológico sobre el lugar que debían ocupar, en el momento de las elecciones de magistrados superiores, los ciudadanos miembros de las clases censitarias más bajas y si la presencia del sorteo, en el marco de este proyecto de reforma y del debate político que provocó, reflejaba una voluntad de introducir, en el procedimiento de las elecciones romanas, un impulso democrático.

1 Recuperamos aquí el debate abierto por historiadores como F. Millar (2002) o A. Yakobson (1999) sobre la dimensión más democrática, a menudo poco reconocida en la tradición historiográfica, de las elecciones romanas. Sobre este punto remitimos a nuestro estudio en: Le rituel du vote, Paris 2010. Podemos discutir ampliamente sobre esta cuestión y las posturas pueden modificarse en función de los diferentes contextos políticos en cada una de las elecciones. Al concentrarnos en la cuestión del lugar del sorteo en el procedimiento de votación de la asamblea de centurias podemos, sin entrar en contradicción con algunos de nuestros análisis anteriores, alinearnos con la visión oligárquica de las elecciones romanas, ya que nos interesaremos, sobre todo, por el sorteo de la centuria prerrogativa. 
Para responder a estas preguntas, organizaremos nuestra reflexión en tres partes. La primera consistirá en examinar los principios fundamentales del funcionamiento de las elecciones romanas, tratando de aclarar las razones por las que se considera una práctica ciudadana concebida para favorecer a las elites. En una segunda parte, nos concentraremos en el desarrollo de las elecciones en los comicios centuriados para estudiar con más precisión la operación de sorteo de la centuria prerrogativa. De ese modo veremos que el sorteo es perfectamente compatible con el principio de igualdad geométrica ${ }^{2}$ (que se opone al de igualdad aritmética) sobre el que se basa el sistema electoral romano. Por último, estudiaremos el proyecto de confusio suffragiorum, atribuido a Graco, y nos interrogaremos sobre si podría consistir en la introducción de un sorteo democrático en las elecciones romanas.

\section{Votar en Roma: ¿una práctica ciudadana reservada a las elites?}

Recordaremos, a continuación, los principios fundamentales de la votación romana, aunque sin volver - lo que supondría un trabajo totalmente distinto - sobre cuestiones de detalle importantes sobre las que, todavía hoy, se continua debatiendo.

El pueblo vota en Roma en dos ocasiones, en las elecciones de magistrados y en la votación de las leyes. Para proceder a votar, en ambas ocasiones, el pueblo romano se reúne en asambleas que reciben el nombre de "comicios". Existen tres tipos de comicios: los comicios curiados, tributos y centuriados. Los primeros dejan de tener un papel político importante bastante rápido bajo la República y no intervienen más que para aprobar el resultado de una elección de magistrados superiores, a quienes, al ser votados, una lex de Imperio les dotaba oficialmente de los poderes que les había confiado la elección. Las otras dos asambleas de votación tienen, sin embargo, un papel político muy importante.

Los comicios tributos permiten elegir a los magistrados inferiores de Roma (cuestores, ediles, magistraturas sin imperium) y votar la mayoría de leyes. Los comicios centuriados eligen a los magistrados superiores (censores, pretores, cónsules, magistraturas con imperium, es decir, con poder militar y civil) y votan las leyes con contenido militar (declaraciones de guerras y aplicación de tratados). El pueblo romano no se organiza del mismo modo, en función de si ha sido convocado a una u otra de estas dos modalidades de asamblea.

Los comicios tributos reúnen al pueblo, dividido en tribus. Se trata de un reparto basado en un criterio geográfico, según el lugar de nacimiento. Existen en Roma, a partir del 241 a.C., treinta y cinco tribus, cuatro de ellas urbanas y treinta y una rurales. Estas

2 Platón (1951), en su tratado de Las Leyes, 757 a-c, diferencia las dos formas de igualdad distinguiendo aquello que, en la igualdad aritmética, hace equivalentes a todos los ciudadanos independientemente de su fortuna y de su posición social, de aquello que, en la igualdad geométrica, concede a cada cual derechos y deberes en función de su rango social: "Hay, en efecto, dos igualdades que reciben el mismo nombre pero que, en la práctica, casi se oponen entre sí en muchos aspectos. Una de ellas, toda Ciudad y todo legislador, logran introducirla en las marcas de honor, aquella que es igual según la medida, el peso y el número; basta con establecerla mediante la suerte en las distribuciones; pero la igualdad más cierta y más excelente no aparece tan fácilmente en todo el mundo. Ella implica el juicio de Zeus y rara vez viene a socorrer a los hombres, pero el escaso socorro que proporciona a las Ciudades o a los individuos solo les favorece; le atribuye más al mayor, al más pequeño, menos, dando así a cada uno según su naturaleza, y, por ejemplo, a los mayores méritos, mayores honores, mientras que a aquellos que son contrarios a la virtud y la educación, les proporciona lo que merecen siguiendo la misma regla". 
tribus conservarán su carácter topográfico pero acabaran por ser hereditarias. Aunque no supondrán un gran cambio, porque el modelo conserva la misma definición del estado civil del ciudadano, que se identifica por sus tria nomina (los tres componentes de la denominación oficial del ciudadano romano: el praenomen, el nomen y el cognomen) y la pertenencia a su tribu.

En cuanto a los comicios centuriados, agrupan al pueblo dividido por clases censitarias y centurias. Su formación data de mediados del siglo VI a.C. y se debería al segundo rey etrusco, Servio Tulio. Las clases censitarias permiten distribuir a los ciudadanos en función de su fortuna. Hay cinco clases y cada una de ellas está, a su vez, dividida en un cierto número de centurias que conforman las unidades de votación. Esta asamblea es, en su origen, una organización militar: las clases censitarias son además, de hecho, clases formadas por guerreros cuyo armamento depende del census, es decir, de la fortuna individual. Cada clase está dividida en centurias (unidad del ejército romano) de iuniores (los más jóvenes) y seniores (los más mayores), lo que equivale, en el ejército, a la distinción entre los activos y la reserva. Como organización militar, esta asamblea es convocada en el Campo de Marte, en el exterior del pomerium (recinto sagrado de la Ciudad, infranqueable para cualquier hombre armado). Sobre la base del concepto de la igualdad geométrica, el principio de esta asamblea es restringir la expresión política al voto de los más ricos. La votación de los comicios centuriados se desarrolla en el orden sucesivo de las clases censitarias y se interrumpe tan pronto como se alcance una mayoría. Sin embargo, siendo 193 el número total de centurias repartidas entre las clases censitarias y teniendo en cuenta que las primeras clases agrupan un total de 98 centurias $^{3}$, es fácil advertir que las últimas clases censitarias, que son las que menos centurias comprenden, son raramente llamadas a las urnas. Es precisamente este hecho el que, a juicio de la aristocracia romana, dota de nobleza al sistema de asamblea de centurias que reserva el voto a las elites de la Ciudad. En los comicios centuriados son, de hecho, las dos primeras clases censitarias las que son llamadas a votar. En los comicios tributos, al contrario, la participación debía ser más amplia. Sin embargo, las diferencias de estas dos asambleas en lo relativo a su composición socioeconómica deben matizarse. Es posible que, mediante los comicios centuriados, se recurriese a las clases inferiores en caso de existir fuertes desacuerdos políticos entre las elites, y los comicios tributos, debido a la sobrerrepresentación de las tribus rústicas en las que se integraban los grandes terratenientes, hacían que el voto se concentrase en las manos de los ciudadanos más ricos.

En el trabajo que aquí presentamos nos concentraremos, específicamente, en el funcionamiento de los comicios centuriados. Este no es lugar para ocuparse de las discusiones sobre la exactitud de la distribución numérica de las centurias entre las diferentes clases censitarias ni del debate sobre una posible reforma del sistema de centurias en el siglo III a.C., que habría supuesto un reparto algo más igualitario en los comicios centuriados, concretamente en el interior de las primeras clases. Lo cual no modifica en nada el principio general que organiza una distribución de la población que proporciona a los más

3 Dieciocho centurias ecuestres y ochenta centurias en la primera clase censitaria (una reforma que se estima del siglo III a.C. cambiará la primera clase censitaria, que pasará de ochenta a setenta centurias, obligando de ese modo a modificar el procedimiento de votación, solicitando el voto de los ciudadanos de la segunda clase censitaria para alcanzar una mayoría). 
ricos una mayor cantidad de votos ${ }^{4}$. Por esta razón, para Cicerón, los comicios centuriados son los “comicios más solemnes, los más legítimos". Son estos comicios quienes, bajo la presidencia de un cónsul, eligen a los magistrados superiores y, a pesar de que el número de leyes sobre las que se les consulta tienda a disminuir, su competencia legislativa permanece intacta, fundamentalmente en lo relativo a las decisiones de entrar en guerra y en la aplicación de tratados.

\section{Comicios centuriados y sorteo de la centuria prerrogativa}

Durante la organización de las votaciones, en los comicios centuriados se hacía un sorteo para decidir cuál era la primera centuria llamada a votar, a la que se conoce como la centuria prerrogativa. Con la reforma fechada, muy a menudo, en la segunda mitad del siglo III a.C, más precisamente en el año 241 a.C., momento en que se alcanzó definitivamente el número de treinta y cinco tribus, la prerrogativa ya no se concedía a los caballeros $^{5}$. Disponemos también de un testimonio de Tito Livio (1958, X, 22, 1), para el año 296 a.C., en el que menciona "las centurias prerrogativas y aquellas llamadas a votar primero". Serían, por lo tanto, las dieciocho centurias ecuestres las llamadas a votar primero $^{6}$. En cambio, si consideramos otros testimonios de Tito Livio después del 241 a.C., podemos ver que la prerrogativa es entonces sorteada entre las centurias de infantería de la primera clase censitaria, al menos en las elecciones consulares (Tito Livio, 2005, XXIV, 7, 12-19; 2003b, XXVI, 22, 2-13; 1998, XXVII, 6, 2)7. Cada tribu estaba representada en la votación centuriada por dos centurias, una de seniores y otra de iuniores. La primera clase incluía, al menos, una centuria de iuniores y una centuria de seniores de cada tribu, lo cual implica que la primera clase estaba formada por setenta centurias. La prerrogativa se sortearía, entonces, entre las centurias de iuniores, lo que equivaldría a sortear una tribu. Para designar a esta prerrogativa, se pueden encontrar expresiones como: "Galeria de jóvenes", que significa: centuria formada por jóvenes de la $1^{a}$ clase de la tribu Galeria. Con la reforma del siglo III a.C., los miembros de la infantería movilizable serían los más directamente implicados en la elección de cónsules y de pretores y quienes tendrían el honor de votar en primer lugar (Nicolet, 1976, 348) .

4 Puede verse una descripción del sistema de centurias en Tito Livio (2003, 43, 12-13), Cicerón (1980, II, 39-40) y Dionisio de Halicarnaso (1961, IV, 16-21).

5 Antes de esta reforma, la prerrogativa se concedía a las dieciocho centurias ecuestres llamadas a votar conjuntamente (primo uocatae): cf. C. Nicolet $(1976,352)$ y Tito Livio $(1958$, X, 22, 1). Cabe destacar que no es fácil identificar el lugar que ocupa el sorteo si todas las centurias ecuestres votan a la vez. ¿Significa esto que la práctica del sorteo coincide con la reforma del año 241 a.C.? No obstante, no parece que C. Nicolet contemple esta hipótesis.

6 Festus (1994, 290 L), citando a Varrón, se refiere también a prerrogativas en plural.

7 Cf. también sobre el sorteo de la prerrogativa: Cicerón (1972, II, 82).

8 Aunque F. X. Ryan $(1995,190)$ considera que si Tito Livio precisa, en los tres casos mencionados anteriormente, que una centuria de iuniores era prerrogativa, es porque una centuria de seniores podía también serlo en otros casos. M. Jehne $(2000,664)$ considera también que la prerrogativa podría ser una de las centurias de iuniores de la $1^{\mathrm{a}}$ clase, o una centuria de la $1^{\mathrm{a}}$ clase, o incluso una centuria elegida entre los equites y la $1^{\mathrm{a}}$ clase. 
Puesto que el sorteo implica una igualdad en la legitimidad de expresar la opinión y de influir, tal vez, en el resultado final, se tenía un especial cuidado en la selección y se excluía, en este primer momento, a los ciudadanos peor considerados, lo que implicaba descartar a los miembros de las dos tribus con peor fama de Roma. Claude Nicolet $(1976,348)$ advirtió la importancia de esta fase de "sorteo":

"No hay ninguna asamblea romana regular que esté libre de esta regla religiosa (convertida muy pronto en regla política) que atribuye una especial importancia, un valor de presagio (omen) y, por lo tanto, un carácter de transmisión o de arrastre a la expresión del primer voto".

Numerosos episodios dan testimonio de la importancia del primer voto, como resultado de un sorteo. En el 214 a.C., durante una votación consular, el voto de la prerrogativa resultó contrario a los deseos del magistrado que presidía la sesión y este decidió suspenderla (Tito Livio, 2005, XXIV, 7-9). En el 211 a.C., la prerrogativa eligió un cónsul que rechazó el cargo y solicitó que se volviera a votar. El segundo voto de la prerrogativa fue seguido por todas las demás centurias (Tito Livio, 2003b, XXVI, 22). Esto explica por qué, en algunos de sus textos, Cicerón $(1938$, I, 103; 1962, 38) califica a la votación de la prerrogativa como omen (presagio).

Esta primera etapa de la elección podía prestarse a manipulaciones (Rosillo López, 2010). En el año 54 a.C., dos candidatos ofrecieron a la centuria prerrogativa diez millones de sestercios a cambio de su voto y de la eliminación de uno de sus rivales (Cicerón, 2002a, $2,14,4)$.

La práctica del sorteo como preámbulo del procedimiento electoral también se producía en los comicios tributos, donde se sorteaba la tribu principium. En el seno de esta tribu, el nombre del primer votante, también elegido por sorteo, era anotado y seleccionado como candidato (Nicolet, 1976, 355 y 383-384). Lo que no sabemos es si se sorteaba o era designado por el magistrado que presidía la sesión. Es muy posible que hubiese una forma de llamamiento.

¿Cuál es el significado del sorteo en estas acciones previas a la votación? Evidentemente no existe relación alguna con cualquier práctica democrática. Esto era así, al menos, en el caso de los comicios centuriados y en el nombramiento de la centuria prerrogativa, donde se hacía un sorteo entre iguales. Este uso del sorteo adquiere un valor religioso y aparece como una forma de presagio muy restrictivo y que condiciona el resto del procedimiento electoral.

\section{El proyecto de los Gracos de confusio suffragiorum y su recuperación en la época de César}

Al final de la República se menciona un proyecto de ley que estaba destinado a transformar completamente el espíritu del procedimiento de votación en el seno de los comicios centuriados. Esta profunda modificación concedería al sorteo un lugar determinante en el proceso electoral con un sentido muy distinto al que tenía en el momento del sorteo de la centuria prerrogativa. 
La reforma propuesta por C. Graco, durante su mandato como tribuno, hace posible reconsiderar completamente el funcionamiento de la asamblea de centurias y atribuir un sentido diferente a la operación de sorteo en el marco de sus reuniones. Puede verse en este texto:

Sed magistratibus creandis haud mihi quidem apsurde placet lex quam C. Gracchus in tribunatu promulgaret, ut ex confusis quinque classibus sorte centuriae uocarentur. Ita coaequata dignitate pecunia, uirtute anteire alius alium properabit.

"Sobre el nombramiento de magistrados, comparto por buenas razones la ley promulgada por C. Graco durante su mandato como tribuno, que ordenó que se sortearan las centurias, para ser convocadas, entre las cinco clases sin distinción; de este modo, habiéndose puesto la dignidad en pie de igualdad con la fortuna, nadie mostrará interés en destacar sobre otros más que por la virtud".

No se trata aquí, por tanto, del sorteo de una sola centuria prerrogativa, sino de un sistema de sorteo ampliado a todo el procedimiento de votación de la asamblea de centurias. Este extracto de una carta enviada a César por el Pseudo Salustio contiene un conjunto de recomendaciones de "política general":

"Que tu primer acto sea arrebatar al dinero su prestigio. Que nunca más sea la riqueza la que conceda más o menos derecho a decidir sobre la vida o el honor de otros; del mismo modo, que ni el pretor ni el cónsul sean nombrados en base a su riqueza, sino en función de sus méritos. En lo relativo a las magistraturas, es natural someterse al juicio del pueblo: reservar a una oligarquía la elección de los jueces, es tiránico; elegirlos en función de su dinero, es deshonesto". (II, 7, 10-11)9.

Este proyecto de confusio suffragiorum, aconsejado a César por el autor de la carta, sería, por lo tanto, el intento de poner en marcha una antigua ley (o más bien proyecto de ley) de los Gracos que permitiría a los ciudadanos de las clases más bajas participar en las elecciones centuriadas. Un estudio de A. M. Suárez Piñeiro (1998) recuerda la continuidad en la acción de los populares, que siempre propusieron una apertura del sistema de votación. Nos encontramos, sin embargo aquí, con dos problemas: el de la autenticidad de la carta y el de que la única mención a esta ley se encuentra en esta carta. C. Nicolet (1959) opta por la autenticidad de la carta de Salustio ${ }^{10}$, debido a su parecido con un pasaje del Pro Murena en el cual se hace mención a un proyecto de Servio Sulpicio Rufo que también conduce a la recuperación de la ley de los Gracos (Cicerón, 1962, 47). Esta reforma se percibió como el modo de restablecer la virtud como único factor decisivo en las elecciones (Dupla, Fatás y Pina, 1994) ${ }^{11}$.

9 París, Les Belles Lettres, texto editado, traducido y comentado por A. Ernout, 1974.

10 Véase también C. Virlouvet (1984).

11 Aunque P. Moreau (2003) recuerda que ninguna reforma de los populares se propuso acabar con la distancia que separaba a los comicios de los contiones. 
El proyecto de reforma plantea varias cuestiones importantes, además de la de su autoría y autenticidad: ¿en qué sentido podría esta generalización del sorteo revolucionar el espíritu de las elecciones romanas, en especial de aquellas que recaían en la asamblea de centurias? ¿Podría decirse que el sorteo aquí propuesto sería representativo de una ideología popularis revelada por un programa de reforma del funcionamiento de las elecciones? ¿Se trataría, en fin, de la introducción de un uso democrático del sorteo en la vida política romana?

El autor de la carta a César presenta las virtudes de esta reforma insistiendo especialmente en que esta permitirá excluir el factor del dinero de la competición entre los candidatos: "habiéndose puesto la dignidad en pie de igualdad con la fortuna, nadie mostrará interés en destacar sobre otros más que por la virtud". De aprobarse la reforma, los candidatos ya no verían justificada su supremacía política únicamente por su riqueza, sino que esta se consideraría tan importante como la dignidad propia de cada candidato; así, el único criterio de diferenciación para los puestos de los magistrados superiores sería la virtud propia de cada cual.

¿Cómo transcurría el proceso electoral antes de la propuesta de reforma? Los comicios centuriados representaban una apuesta política extremadamente importante, ya que daban lugar especialmente a la designación de los cónsules, los magistrados supremos. La corrupción en las primeras clases censitarias estaba, por tanto, muy presente. Se trataba de elecciones entre personas procedentes de las mismas clases censitarias: la posesión de una elevada fortuna cualificaba tanto a los candidatos como a sus electores, ya que el sistema de voto en esta asamblea solamente daba un poder electoral real, ya lo hemos visto, a los ciudadanos de la clase ecuestre y a las dos primeras clases censitarias ${ }^{12}$. Las prácticas de corrupción podían, desde luego, llegar a todas las capas de la población, incluso aunque los ciudadanos de las últimas clases censitarias no fueran llamados a votar en la mayoría de los casos, ya que los candidatos podían beneficiarse de su apoyo para mejorar su popularidad y podían ser útiles electoralmente por medio de los lazos clientelares. G. Lobrano (1997) afirmaba que el magistrado no solamente recibía su potestas del pueblo, sino que estaba bajo la potestas del pueblo. El vínculo indisoluble entre el pueblo y el otorgamiento de poderes estará siempre presente en la historia de Roma, más allá de los cambios de régimen. Dos expresiones emblemáticas de la época de campaña y competencia electoral ilustran este lugar determinante otorgado al pueblo: supplicare populo Romano / appellare populum. La supplicatio pasa por la concesión de largitiones al pueblo. La appellatio consiste en ser capaz de llamar a los electores por sus nombres. Para estos dos tipos de maniobras de seducción del electorado el candidato necesitaba ayuda: recurría a diuisores y a nomenclatores. Todo este vocabulario se utiliza ampliamente en el Commentariolum Petitionis, escrito por Quinto Cicerón para su hermano, Marco Cicerón, candidato al consulado del año 63 a.C. Por tanto, estaríamos realmente ante un "voto-transacción". Todo esto se basa en valores romanos fundamentales, constitutivos del mos maiorum: la generosidad de los futuros representantes del pueblo con respecto a este último, la liberalitas que sostiene el evergetismo (Manning, 1985; Cicerón, 2002b, 30-31; Cicerón, 1970, III, 118), la solidez de las relaciones clientelares y la amicitia, aunque Cicerón distingue muy claramente aquella que se construye en contexto

12 Aunque parece que las elecciones consulares y pretorianas solicitan, de vez en cuando, los votos de la plebe, esto se limita a contextos políticos agitados y a situaciones de perturbación política e incluso disturbios electorales. 
electoral ${ }^{13}$. Pero este funcionamiento de la campaña y de la competencia electoral plantea igualmente la cuestión política de la implicación en las elecciones de las capas más pobres del cuerpo cívico y, por tanto, electoral romano. Según A. Yakobson, las largitiones son la prueba manifiesta de que el voto de los más pobres debía contar. Otros, como E. S. Staveley, estiman, por el contrario, que las largitiones no estaban destinadas a comprar los votos de los primeros beneficiarios de las mismas, sino de sus ricos patrones ${ }^{14}$. El período que se abre con los consulados repetidos de Mario y se cierra con la llegada al poder de Augusto como Princeps de Roma está marcado por una creciente competencia electoral. El surgimiento de figuras políticas fuertes y de fracturas ideológicas en el Senado y las magistraturas son las causas directas de este desbordamiento de la vida electoral, que podía llegar al bloqueo cuando las situaciones de violencia se volvían incontrolables. En tal clima, la seducción de los electores ocupaba un espacio considerable. Así, se pasa fácilmente, en repetidas ocasiones, de un transcurso normal e institucionalmente reglado de la competencia electoral, a maniobras que incluían métodos ilegales de corrupción calificados como crimen ambitus y contemplados en una legislación prolífica e incapaz de calmar la situación.

\section{4. ¿Una revolución democrática?}

¿Cuál podía ser el cambio ocasionado por la reactivación de la reforma de los Gracos de generalización del sorteo de las centurias? Una práctica social tan extendida como el clientelismo electoral impide pensar que la corrupción hubiera podido desaparecer por el simple hecho de promulgar una nueva ley. Pero si todas las centurias - como consecuencia de su designación por sorteo- pudieran jugar un rol decisivo en el resultado final del voto, entonces la influencia de los candidatos habría disminuido de manera natural, debido al incremento del número de personas a “corromper". Así, solamente las cualidades propias de cada candidato podrían garantizarle recibir los sufragios de una centuria. Por otra parte, en términos de voto de clase, se abandonaría un sistema de voto hecho por y para ciudadanos ricos, capaz de garantizar los privilegios de su clase social.

Por lo tanto, la reforma sería una verdadera revolución en una sociedad regida por la jerarquía censitaria, que asocia la noción de capacidad política de los ciudadanos a su riqueza personal. En efecto, la medida supone una manera de expulsar el dinero de la campaña electoral y de las propias elecciones, ya que, gracias a esta generalización del sorteo, los electores estarían en pie de igualdad, sin importar su riqueza. El sistema se alejaría de la igualdad geométrica para aproximarse a la igualdad aritmética. Más allá de la transformación que suscitaría en las modalidades de designación de los magistrados superiores de la ciudad, el proyecto de reforma hace frente a la propia estructuración de las relaciones sociales entre las élites y el resto del pueblo. Su carácter radical explica que jamás se pudiera aplicar, ni en la época de los Gracos ni en la de César.

13 Comm. Pet., V, 16 (2007): "Pero en una campaña electoral, el sentido de la palabra amigos es más amplio que durante el resto de la vida. Aquel, sea quien sea, que muestre efectivamente buenas disposiciones respecto a ti, que cultive tu simpatía y frecuente asiduamente tu casa debe contarse entre tus amigos".

14 El debate sobre el vínculo entre la corrupción electoral y el sistema clientelar está resumido en Morstein-Marx (1998). 
Al margen del escaso éxito del proyecto, ¿puede verse en él la prueba de la existencia de una ideología democrática defendida por el "partido" de los populares? No podemos retomar aquí todo el debate historiográfico en torno a la existencia de un partido de los populares opuesto a un partido de los optimates, defendiendo ambos dos ideologías opues$\operatorname{tas}^{15}$. La palabra ideología puede, efectivamente, tener varios significados, que incluyen tanto el desarrollo de sistemas globales de transformación de la sociedad como versiones más abiertas. En esta última interpretación, la ideología se refiere a doctrinas que cumplen una función social y política y permiten a los individuos responder a las exigencias de sus condiciones de existencia. Tanto para los Gracos como para los populares que los sucederán, ya se acepte o no hablar de ideología democrática, es forzoso reconocer que tal reforma del procedimiento de voto en los comicios centuriados remite a una concepción orgánica de la ciudad opuesta a aquella en la que se basa el funcionamiento originario de esa misma ciudad. Por tanto, lo que se propone en esta revolución del sistema de centurias es, en cierta manera, una nueva visión del mundo cívico que contradice los principios originales sobre los cuales fue fundado en los primeros tiempos de la vida política de la Vrbs. Y esta nueva visión del sistema político romano la defiende un grupo social que, como Cyril Courrier (2014) ha demostrado, compartía una unidad y una cultura común, a pesar de que existieran diferentes grupos en su seno.

Sin embargo, ¿puede calificarse como democrática esta nueva visión de la organización política de la ciudad? Se trata de dar a todos los ciudadanos, independientemente de su pertenencia a un grupo censitario concreto y, por tanto, de su fortuna, el mismo derecho de voto. Esta igualdad está garantizada por una generalización del sorteo entre las centurias. Así, las cinco clases censitarias pueden participar en las elecciones de los magistrados superiores. Parece difícil, ante esta toma de responsabilidad política del populus Romanus en su conjunto y no solamente de sus representantes más ricos, no calificar tal proyecto como demo-

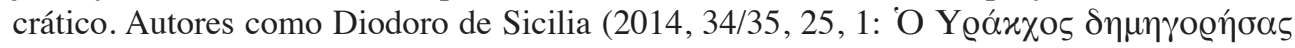

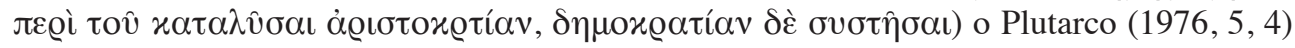
no han dudado en calificar como "democrático" el proyecto político global de Cayo Graco (Botteri y Raskolnikoff, 1983). La cuestión de los procedimientos electorales era uno de los elementos del debate político que enfrentaba, desde los Gracos hasta el fin de la República, a los populares y los optimates. Lo testimonia este pasaje de De Legibus de Cicerón (1959, III, 10), escrito en la misma época que la carta a César:

Creatio magistratuum, iudicia populi, iussa uetita cum suffragiis consciscentur, ea optimatibus nota, plebi libera sunto.

"Cuando la elección de los magistrados, los juicios del pueblo, las leyes o las prohibiciones son objeto de un voto, el sufragio se hará con el conocimiento de los nobles y libremente para el pueblo".

La interpretación de esta lex de suffragiis plantea problemas. L. Troiani (1987) la entiende de la siguiente manera: el propósito de Cicerón es hacer de tal manera que, en los

15 Sobre esta extensa cuestión, remitimos a un artículo de Ferrary (1997) y, más recientemente, al libro de Robb (2010). Por último, los trabajos recientes de Le Doze (2010) han vuelto a ocuparse ampliamente de este debate. 
comicios electorales, legislativos o judiciales, el pueblo sea guiado para eliminar cualquier posibilidad de discordia o de rechazo y para que la autoridad de los optimates pueda ponerse en valor. Según Troiani, podemos entender esta ley de manera diferente a la interpretación generalmente admitida por los historiadores. Se suele considerar que su objetivo es admitir el voto secreto, con la condición de que las tabellae se muestren a los boni ${ }^{16}$. La interpretación de L. Troiani es diferente: los optimates deberán votar después de haber anunciado claramente sus intenciones de voto. De esta manera, podrán controlar el "voto libre" del pueblo. Desde este punto de vista, la libertad de voto del pueblo consistiría en escoger entre los candidatos seleccionados por los optimates. Esta reforma no haría más que confirmar y generalizar lo que de hecho ya ocurría, en la práctica, con el voto de la prerrogativa y anuncia las prácticas electorales de los últimos años de la República y del principado. Es una manera, para los optimates, de limitar los efectos de la instauración del voto secreto. Frente a su amigo Ático, que defiende una constitución "sometida al poder de la aristocracia" y representa a los optimates más conservadores, y frente a su hermano Quinto, que defiende el regreso al voto a mano alzada y desea "no lo que estamos en disposición de imponer al Estado, sino lo mejor", Cicerón propone en este diálogo una solución más realista y más moderada. Aún tiene confianza en la buena fe del pueblo y piensa que, bien aconsejado y bien dirigido, siempre vota correctamente. Según él, se puede otorgar la libertad al pueblo, pero solamente con la condición de "que los nobles tengan una gran influencia y hagan uso de ella". Desde luego, no hay "nada mejor que el voto en voz alta", pero parece difícil imponerlo, ya que supondría, lisa y llanamente, la supresión de las leyes tabularias. Si no se puede abolir el voto por tabella, en cambio es posible abolir las leyes que reforzaron el secreto del voto "impidiendo mirar la tablilla, preguntar, interpelar...". En este sentido hay que entender la misteriosa fórmula que Cicerón utiliza al principio de este diálogo: los sufragios deben "dejarse al conocimiento de los nobles", pero "libres para la plebe". Cicerón retoma ahí su concepción muy oligárquica de la libertad del pueblo. Como recuerda C. Nicolet (1976: 429-430) en el Métier de citoyen: "En Roma, donde el poder real está repartido (...) entre el pueblo en sus asambleas, el Senado y los magistrados superiores (...), lo que importa, a fin de cuentas, no es tanto saber si el pueblo gobierna, como saber si es libre, es decir, si puede hacer pleno uso de sus derechos". Por tanto, la libertad del pueblo solo puede entenderse en la República romana en relación, como hemos visto, con la auctoritas del Senado. Esta visión de los vínculos entre libertad del pueblo y control de los nobles se encuentra también en la visión del Estado defendida en el libro II de De Republica (Cicerón, 1980, II, 55-56).

Así, se ve claramente cómo el proyecto de reforma sugerido a César y el pensado por Cicerón se sitúan, en el mismo contexto político de la Roma tardo-republicana, en los dos extremos de la visión de la organización del sistema electoral y de la manera de concebir el papel político de las diferentes capas sociales de la población ciudadana de Roma. Por otra parte, podemos señalar los límites de la dimensión verdaderamente democrática del proyecto de Cayo Graco: en él no se pone en cuestión, de manera fundamental, la igualdad geométrica, ya que las centurias siguen conservando su composición. El proyecto de C. Graco no cuestiona el sistema esencialmente desigual, en el sentido de la igualdad aritmética, de las unidades de voto romanas. Las últimas clases censitarias siguen teniendo, en el nuevo

16 Cf. la interpretación de Salerno (1999: 15 y ss). 
sistema, muchas menos centurias que las primeras; por tanto, su peso electoral sigue siendo muy reducido. En resumen, el voto romano nunca fue un bien común que se repartiera a partes iguales.

Este proyecto de confusio suffragiorum sufrió un segundo fracaso y las elecciones bajo César no se inscribirán en la línea de esta reforma; aunque la dimensión oligárquica del voto de centurias quedó en un segundo plano a causa de las indicaciones de voto procedentes del propio César:

"Para los cónsules, las cosas tenían lugar así: los demás magistrados eran, en principio, designados por la plebe o por el conjunto del pueblo, conforme a la tradición, ya que César no había aceptado su designación; pero en la práctica, era realmente él quien los designaba" (Casio, 1961, 43, 46, 3-6).

\section{Lex Antonia de magistratibus:}

"Compartió con el pueblo el derecho a elegir a los magistrados, decidiendo que, salvo los candidatos al consulado, el pueblo elegiría a la mitad de los candidatos y él mismo a la otra mitad. Sin embargo, César hacía saber sus candidatos por medio de discursos dirigidos a las tribus con esta simple fórmula: el dictador César a tal tribu. Yo os recomiendo a tal y a tal, para que tengan la dignidad de vuestros sufragios" (Suetonio, 1981, XLI, 4).

¿Por qué no pudo triunfar tal proyecto de generalización del sorteo en el sistema de centurias? En primer lugar, a causa del fracaso global de la política de los Gracos, a pesar de su evidente legado posterior. En segundo lugar, porque esta medida "revolucionaria" era contraria al principio fundamental del sistema de centurias y conllevaba una ruptura con el mos maiorum. En fin, porque en Roma, el sorteo del voto debía hacerse entre iguales. Se trataba de un azar controlado dentro del grupo que incorporaba el sorteo. Roma no entiende el sorteo como un instrumento democrático. El voto, legislativo o electoral, sitúa en el corazón del proceso político romano el iussum populi, al cual se le confiere una dimensión casi sagrada que incluso César y los emperadores posteriores no tocarán. Si existe democracia en Roma, está presente en esta convocatoria ritual y simbólica del populus, sea cual sea la parte real del grupo que participa de manera efectiva en la elección de los futuros magistrados de la ciudad. Ahí se encuentra el gran elemento de continuidad política entre la República y el Imperio. El resto, ya lo califiquemos de ideología o de táctica política, no puede remontarse más allá de aquello que otorga valor sagrado al voto romano, esto es, la convocatoria regular de aquel que expresa el iussum final de una decisión política tomada por la nobilitas. La República romana sigue siendo una oligarquía que sacraliza el iussum populi.

\section{Referencias}

Botteri, P. y Raskolnikoff, M. (1983): "Diodore, Caius Gracchus et la Démocratie”, en C. Nicolet: Demokratia et Aristokratia, París, pp. 59-101.

Casio, D. (1961): Histoire romaine, traducción de E. Cary, Loeb Classical Library, Londres. 
Cicerón, M. T. (1938): De Diuinatione, traducción de H. De la Ville de Mirmont, Les Belles Lettres, París.

Cicerón, M. T. (1959): De Legibus, traducción de G. de Plinval, Les Belles Lettres, París.

Cicerón, M. T. (1962): Pro Murena, traducción de A. Boulanger, Les Belles Lettres, París.

Cicerón, M. T. (1970): De Officiis, traducción de M. Testard, Les Belles Lettres, París.

Cicerón, M. T. (1972): Philippiques, traducción de P. Wuilleumier y A. Boulanger, Les Belles Lettres, París.

Cicerón, M. T. (1980): De Republica, traducción de E. Bréguet, Les Belles Lettres, París.

Cicerón, M. T. (2002a): Correspondance, traducción de L.-A. Constans, Les Belles Lettres, París.

Cicerón, M. T. (2002b): Laelius. De Amicitia, traducción de R. Combès, Les Belles Lettres, París.

Cicerón, Q. (1997): Petit manuel de campagne électorale, traducción de N. Waquet, Rivages, París.

Courrier, C. (2014): La plèbe de Rome et sa culture (fin du Ile siècle av. J.-C. - fin du Ier siècle ap. J.-C.), Roma.

Dionisio de Halicarnaso (1961): Antiquités romaines, traducción de E. Cary, Loeb Classical Library, Londres.

Diodoro de Sicilia (2014): Bibliothèque historique, traducción de P. Goukowsky, Les Belles Lettres, París.

Dupla, A., Fatás, G. y Pina, F. (1994): Rem Publicam Restituere. Una repuesta popularis para la crisis republicana : las Epistulae ad Caesarem de Salustio, Univ. de Zaragoza.

Ferrary, J. L. (1997): “Optimates et Populares. Le problème du rôle de l'idéologie dans la politique", en Hinnerk Bruhns, J.-M. David y W. Nippel (eds.): Die Späte Römische Republik. La fin de la République romaine. Un débat franco-allemand d'histoire et d'historiographie, École française de Rome, Roma, p. 228 y ss.

Festus (1994): Abrégé des Hauts faits du peuple romain, traducción de M.-P. Arnaud-Lindet, Les Belles Lettres, París.

Hollard, V. (2010): Le rituel du vote. Les assemblées du peuple romain, CNRS Éditions, París.

Jehne, M. (2000): "Wirkungsweise und Bedeutung der centuria praerogativa", Chiron, 30.

Le Doze, Ph. (2010): "Les idéologies à Rome: les modalités du discours politique de Cicéron à Auguste", Revue Historique, 2010/2, n 654, pp. 259-289.

Lobrano, G. (1997): "Popolo e legge: il sistema romano et la deformazione moderna", en $\mathrm{S}$. Roman et al. (eds.): Nozione, formazione e interpretazione del diritto dall'età romane alle esperienze moderne. Ricerche dedicate al professore Filippo Gallo, Jov. Ed., vol. I, Nápoles, pp. 453-487.

Manning, C. E. (1985): "Liberalitas: the decline and rehabilitation of a virtue", $G \& R, 32$, pp. 73-83.

Millar, F. (2002): The Roman Republic and the augustan revolution, Ed. de M. Cotton \& G.M. Rogers, Univ. North California Press, Chapel Hill.

Moreau, P. (2003): "Donner la parole au peuple? Rhétorique et manipulation des contiones à la fin de la République”, en S. Bonnefou, P. Chiron, D. Ducard, et al. (eds): Argumentation et discours politique. Antiquité grecque et latine, Révolution française, Monde contemporain, Rennes, pp. 175-189. 
Morstein-Marx, R. (1998): "Publicity, popularity and patronage in the Commentariolum Petitionis", $\mathrm{Cl}$. Ant, 17, n 2, pp. 259-288.

Nicolet, C. (1959): “Confusio Suffragiorum: à propos d'une réforme électorale de Caius Gracchus", Mélanges d'Archéologie et d'Histoire, pp. 145-210.

Nicolet, C. (1976): Le Métier de citoyen dans la Rome républicaine, París.

Platón (1951): Les Lois, edición y traducción de E. Des Places, Les Belles Lettres, 1951.

Plutarco (1976): Vie de les Gracques, traducción de R. Flacelière y E. Chambry, Les Belles Lettres, París.

Robb, M.-A. (2010): Beyond Populares and Optimates. Political Language in the late Republic, Stuttgart.

Rosillo López, C. (2010): La corruption à la fin de la République romaine (Ilè-Ier s. av. J.-C.), Stuttgart.

Ryan, F. X. (1995): "Sexagenarians, the Bridge, and the centuria praerogativa", RhM, 138.

Salerno, F. (1999): Tacita libertas, Jov. Ed., Nápoles.

Salustio (Pseudo-) (1974): Lettres à César. Invectives, texto editado, traducido y comentado por A. Ernout, Les Belles Letres, París.

Suárez Piñeiro, A. M. (1998): "La reforma del sistema electoral romano durante el ultimo siglo de la República", Gallaecia, 17, pp. 425-446.

Suetonio (1981): Vie de César, traducción de H. Ailloud, Les Belles Lettres, París.

Tito Livio (1958): Histoire romaine, livre X, traducción de E.-T. Sage, Loeb Classical Library, Londres.

Tito Livio (1998): Histoire romaine, livre XXVII, traducción de P. Jal, Les Belles Lettres, París.

Tito Livio (2003a): Histoire romaine, livre I, traducción de R. Bloch, Les Belles Lettres, París.

Tito Livio (2003b): Histoire romaine, livre XXVI, traducción de P. Jal, Les Belles Lettres, París

Tito Livio (2005): Histoire romaine, livre XXIV, traducción de P. Jal, Les Belles Lettres, París.

Troiani, L. (1987): “Alcune considerazione sul voto nell'antica Roma (a proposito di Cic., Leg., III, 10)", Athenaeum, 1987, 75, fas. III-IV, pp. 493-499.

Virlouvet, C. (1984): "Le sénat dans la seconde lettre de Salluste à César", en C. Nicolet (ed), Des Ordres à Rome, París, pp. 101-141.

Yakobson, A. (1999): Elections and electioneering in Rome. A study in the political system of the Late Republic, Steiner, Stuttgart. 